\title{
Democratization of Learning through Thematic Assignment
}

\author{
Christophil S. Medellu ${ }^{1}$, S. Lumingkewas ${ }^{2} \&$ J. F. Walangitan ${ }^{3}$ \\ ${ }^{1}$ Department of Physics, Faculty of Science and Mathematics, University of Manado, Indonesia \\ ${ }^{2}$ Department of Chemistry, Faculty of Science and Mathematics, University of Manado, Indonesia \\ ${ }^{3}$ Teacher at SMA Katolik Aquino Manado, Sulawesi Utara, Indonesia \\ Correspondence: Christophil S. Medellu, Department of Physics, Faculty of Science and Mathematics, \\ University of Manado, Indonesia. E-mail: chmedellu@yahoo.com
}

\author{
Received: October 16, 2014 Accepted: December 2, 2014 Online Published: March 29, 2015 \\ doi:10.5539/ies.v8n4p111 URL: http://dx.doi.org/10.5539/ies.v8n4p111
}

\begin{abstract}
This article describes the results of research on learning democratization in Sangihe. This study is the first year of a five-year plan. Long-term goal of this research is to create the democratic science learning in schools. Democratic learning model was developed through thematic assignment, involving the participation of parents and communities. This study covers three main stages, namely designing and developing instruction, implementation and evaluation. Democratization of learning was analyzed based on indicators of student's activities, the role of teachers and parents. The results showed that the collaboration of teachers, students and parents in the development of the design can initiate the process of democratization. Implementation of thematic assignment instruction involving parent's role, can motivate students and encourage the activities of student groups to increase from the first to tenth meeting. Thematic assignment on environmental issues, were easily understood by students and allow parents act as learning partners, motivator and facilitator. Dialogical assessment was encourages student groups to improve the learning activity from the initial to the next meeting. The final evaluation results showed that the study group interaction in a democratic climate can reduce individual differences and establish an open collaboration, so the groups learning outcomes fairly homogeneous.
\end{abstract}

Keywords: democratization of learning, thematic assignment, context-concept

\section{Introduction}

Policy of students based activities in learning has been established since decades ago. In fact, the teaching process in Sangihe still centered on teacher (Tumangkeng, 2013; Marpaung, 2014; Rasubala, 2014). Factors inhibiting the development of student activity-based learning were: (1) lack of teacher experience to develop learning materials (Marpaung, 2014; Rasubala, 2014), (2) lack of experience of teachers develop students' activity-based learning methods (Medellu, 2013), (3) teaching orientation toward the national evaluation that emphasizes the concept (Medellu, 2013; Raturandang, 2013). Survey of thematic assignment in Sangihe, shows that learning materials sourced only from books and not take the surrounding environment (Mandang, 2013; Tumangkeng, 2013; Rende, 2013). Students are not confronted to science objects in form of real world. This has contributed to the difficulty for students to develop the concept further (Smith, 1999). McDermott (1993) suggests that students have difficulty in establishing the basic concepts of physics through traditional learning that emphasizes material from the textbook. Popov (2008) suggests that students can be trained to understand the physics concepts through real world around it. Students can learn the logic of the laws of physics that apply in nature.

The survey results indicate that students are not accustomed to cooperative learning and interacting in small groups doing science process (Tumangkeng, 2013; Rende, 2013). The instruction of learning interactions in small groups is very important in the development of activity-based learning students. Based on research results, the American Institute of Physics also suggests that small group collaborative learning is the most convincing instruction for environment learning (Heller et al., 1992). The survey results also indicate that a given assignment is not done carefully (Raturandang, 2013). According to Walberg (1999), an assignment with feedback by the teacher, have the greatest effect in the learning process of students. The results of the study by Keith and Cool (1992) showed that at the high school level, extra time of 30 minutes every day to do the work, will enhance the students' GPA by half a point. 
Thematic learning is a systematic attempt to address the aforementioned problems. Thematic teaching is a pedagogic model which based on the choice of the theme or topic of study. This model deals with some pedagogic methods like learning outside the classroom, team teaching, and community learning (Northwest Regional Educational Laboratory, 2005). Several important issues related to the thematic learning are: (1) transdisciplinary learning, (2) confront the students with the real world around him, and the relationship with a global phenomenon, (3) individual differences in learning, (4) learning based on research, (5) build a learning community and school-community relations (Medellu, 2014). The most common models are the thematic learning units, in which a theme studied from several field studies (Barton \& Smith, 2000). The advantage of integrated thematic instruction is the flexibility of teachers to design instruction, in line with the student needs, and then the students can take a multiple sources of learning (Wood, 1997). According to Fogarty (1997) thematic instruction may involve skills such as reading, thinking, remembering and writing real-life contexts that can encourage creative exploration. Instruction is integrated in the unit theme, allowing performed authentic assessment (Barton \& Smith, 2000).

The real world as an object of thematic teaching, will to focus learning activities outside the classroom. Learning outside the classroom can be designed to enable students to observe various real world (Pendrill, 2005), conducted an analysis to connect the facts with conceptual knowledge (Bransford et al., 1999), to exchange experiences with other students (Krogh, 1990) to build a knowledge more complex and complete. Learning outside the classroom, improve their knowledge and understanding of natural systems and processes that ultimately builds responsibility to the environment (Higgins, 2002). Through learning outside the classroom, the learning process as a dynamic system: "the subject-activity-object (Stetsenko, 2005) will develop authentically. According to Popov (2008), the context of learning in the form of the real objects and everyday life, are not explicit as in the laboratory, the context must be found and studied. Context can be seen from the perspective of different concepts. Sweetser and Fauconnier (1996) cited by Popov (2008) explains that students will access different information in different contexts. Through a variety of contexts, students can understand more fully and more clearly the concepts, encourage critical thinking in selecting alternatives, and responsible for the process of learning (Beane, 1997). Learning outside the classroom is not just technical learning, but an opportunity to understand the relationships in the real world (Broda, 2007).

Thematic learning was developed based on research activities. Students are faced with the facts and phenomena of physical, social and interaction, to build the relationship between the context and their knowledge. The results showed that the students can understand the problems in the real world if he was faced to search relationship and the integration of these ideas in an authentic context (Bransford et al., 1999; DiSessa, 2000; Linn \& Hsi, 2000). Noel (2006) designed a learning project that focuses on inquiry-based learning environment. Thematic instruction can be developed in a variety of approaches. Students can be instructed to discuss the concepts, then make observations, measurements, analyze and link up with the concept of context. Students can also be instructed to start from identifying the object, measuring, analyzing and then formulate the relationship between the context and concept. Thematic instruction must be open to allow students to develop ideas and creative activities.

Thematic learning about the environment should build democratization of learning. John Dewey (Smith, 1999) view learning as a democratic process. Democratization of learning provided more flexibility to the students to develop experience, to meet the needs, while performing social interactions. Most schools have not conditioned the democratization of learning. Most schools in North Sulawesi placing students as subjects who received information from the teacher. Ozcan (2005) suggested that schools should be democratic in learning by setting the same access and diversify learning. Learning activities outside the classroom (Popov, 2008) provide the best opportunity for students to acquire knowledge, enriching experiences with different sensitivity to develop personal character. Fettes (2013) suggested that the practice of democratic learning can strengthen the relationship between experience and imagination. Student needs the strengthening of the relationship between experiences and science concepts through democratic-thematic learning.

Our team developed a thematic assignment instruction-based learning that was flexible to allow students develop the democratic process of learning. Development and implementation of learning process involving school leaders, teachers, parents and the community. According to Ozcan (2005), democratic schooling must be supported by all personnel involved in the school management. Democratization of learning was done at the stage of the development of instruction, implementation and evaluation. At this stage of development, teachers, students, parents and the community together to discuss, formulate materials and activities relevant to the environment and their experiences, to be integrated in the basic instructional design. In the implementation phase, the teacher acts as organizer, facilitator and assessor. The role of the teacher as an organizer and facilitator needs 
to encourage students in communication, group discussions and various forms of collaboration in developing critical thinking skills (Popov, 2008). Parents play an important role in the democratic process of a child learning (Bekoe \& Quartey, 2013). Aref et al. (2009) suggested six categories or types of participation of parents/community toward education namely: strengthening, partnership, interaction, consultation, provision of information, and manipulation. As facilitators, parents and the community provide reinforcement of the democratic learning principles such as: education based on the human right to life, development of social dialogue and critical thinking. Thematic assignment material formulated from the environment issues. Learning objects (context) of the thematic assignment are the fact/natural phenomena and social culture. Materials and learning activities was integrating science concepts and processes in the context of the thematic assignment. According to Higins (2002), materials and learning activities like these, potentially to increase the students' knowledge and understanding of the systems and processes in nature. Thematic assignment material and activities confronting students to authentic problems (Popov, 2008), which was designed with two approaches: concepts-context and context-concept. Instructional of thematic assignment is varied in complexity, corresponding to middle and high school education. Learning activities instruction was flexible for developed in the form of communication, attention, thinking, observing, moving, and working individually or in groups. The learning activities ensure the development of multiple-intelligence (Stephens, 2007).

\subsection{Objective}

- The long-term goal of this research is to create the democratic science learning in schools across the North Sulawesi. Democratization of science learning in schools was developed through action research conducted by a team from the State University of Manado. The first year (2014) was the basic research on the democratization process of learning, which was implemented in Sangihe.

- The purpose of the first year study was to evaluate the democratization process of learning through stages: (1) the design of learning materials sourced from environmental issues, 2) implementation of the thematic assignment, and (3) evaluation of the process and outcomes of learning.

\section{Research Methods}

\subsection{Research Procedure}

This study was the first step to building a democratic process of science learning through thematic assignment. Themes of assignment include the strategic issues in the study area, likes: landslides, water cycle and the availability of clean water, coastal erosion, mangrove forests and energy. This article discusses the results of thematic assignment of landslides. Subjects of study were the students of middle and high school. Stages of this research and development were as follows:

Designing of basic instructional thematic assignment. Designing of the basic instruction, conducted over four months: from March to June 2013. Learning material includes: concepts, concepts network across fields of study, and context (facts and phenomena of nature, social and culture). Learning processes were the student activities in groups supported by parents and community.

Survey of the sites for the development of instructional materials and activities as well as the determination of the school. Object of survey covers natural conditions and socio-cultural related to assignment themes.

Try out and revision of instructional design. Instructional design were developed with the input of local elements (survey results) was tested on groups of middle and high school students. After try out and revision, the team conducted a teaching simulation. This simulation aims to develop the variations of the learning activities and setting a time of learning. Simulation was important to avoid differences in the implementation of assignment, procedures of field activities, and learning strategies (Letterman \& Dugan, 2004; Wentworth \& Davis, 2002).

Developing the instructional design in research area. This stage was the development of instructional design in detail, in line with the environmental conditions, and the targeted students. Developing of instructional design, performed by the research team, teacher of science and math, students, parents and the community. Developing of instructional design include the development of instructional materials, learning activities, and manufacturing of equipments for observation or field measurement.

Implementation of thematic assignment. Thematic assignment instruction performed by the students in groups, to follow the syntax of learning method. Basically, the learning method was the student based activities that are inquiry and problem solving. Teams of teachers of Science and Mathematics, and researchers acts as a facilitator. Mechanisms of facilitating follow the material being discussed. Mathematics teacher and researchers with mathematical background, acts as facilitator for mathematical topics. The other teacher and research members act as evaluators. Parents and communities can act as leaning partners or facilitators. Parent's role was depends 
on their knowledge and experience about the matter and activities. Evaluation of the learning process using observations form which are designed to follow the science process. The evaluation of learning process was focused on the skills and teamwork of students. The evaluation process was also based on a form of thematic assignment instructions. Performance evaluation conducted at the end of the learning activities. Performance evaluation to measure the student's knowledge on concepts, relation between concept and context, relation between concepts of subject areas (physics, biology and mathematics). Evaluation of learning programs including perceptual evaluation of students, teachers, parents and the community, held at the end of program. This evaluation emphasized on the affection of the usefulness of material and activities, as a reflection on social behavior, strengthening local wisdom, the implementation of government programs. At the end of implementation of thematic instruction, students expressed the personal commitment related to its role in the utilization of resources, environmental management, enforcement of local knowledge, a critique of the social behavior.

\subsection{Variable of Assessment of Learning Democratization}

Assessment of learning democratization conducted from development stage to implementation and evaluation stage. Assessment of learning democratization was done for teachers, students, and parents/community. At the development stage, indicators of democratization of teachers role were: (1) the input of material (physical, social, cultural), (2) inputs of learning activities relevant to the principles of democratic learning, (3) input of dialogue and varied evaluation, in line with the students conditions, (4) input for involvement of parents/communities role to support the democratization process of learning. Indicators of democratization of the students role were: (1) input of experience relevant to the theme, (2) inputs of alternative activities, (3) input for democratic assessment and evaluation, (4) correction/revision based on tryout of instructional design (such as systematic activities, grouping of students, allocation of time for learning). At the development stage, the indicator of democratization of parents /community role were: (1) the input of local element needed by community, (2) input of activities required by the community, (3) input of variation of students condition and needs for improvement, (4) input of community and parents role, to support the school management. At the development stage, data for teachers, students and parents gathered using the checklist.

In the implementation phase, the indicator of the democratic role of the teacher were: (1) initiatives / activities developed by teachers to enable the interaction of groups of students, (2) the initiative to create the learning dialogue with students and parents/community, (3) a positive response was given to students during the groups interaction and with parents, (4) the solution of social problems relevant to the proposed by students, parents and community. Indicator of democratic activity of students during the implementation of thematic assignment were (1) asking questions relevant to the material and procedures, (2) initiatives to develop alternative of relevant activities, (3) proposed the needs for facilitation services by a team of researchers and teachers, (4) ask the problems raised during the learning process, (5) initiative to do the assignment autonomously with material consistent to thematic assignment. Indicator of the democratic role of parents were: (1) conduct a dialogue with a team of researchers and teachers during the learning process, (2) develop a choice of activities based on experience, relevant to the thematic assignment instructions, (3) develop alternative activities for students, relevant to the material that are being implemented. For all indicators, data obtained using the checklist.

At the stage of evaluation, assessment of democratization was done for the students only. Indicators of democratization in the evaluation phase were: (1) to propose a clarification of the assessment process at each stage of the assignment, (2) propose a clarification on the results of the evaluation of learning outcomes, (3) the openness to receive an objective assessment, and satisfaction with the process and learning outcomes, (4) motivation to learn and do the work of better quality, after getting the results of the evaluation (process and outcomes). Acquisition of data indicator (1) and (2), using the checklist, while the indicator (3) and (4), using a questionnaire. Data obtained from the check list for all stages of the assessment of democratization, was used to obtain qualitative information about the reason for the response of teachers, students, parents / community. The tracking information was also building a dialogical relationship between researcher team- teacher - student parents and community.

\subsection{Analysis and Presentation of Research Results}

Democratization of learning data at the development stage analyzed and presented descriptively. Democratization of learning data at the implementation stage analyzed and presented graphically to show the development from the beginning to the end of the activity. The relationship between indicators of student activity during the learning process with the role of teacher and parents / community, were analyzed using analysis of rank correlation (Spearman rho). The results also present the relationship between mastery of the concepts of 
science and mathematics, using product moment correlation.

\section{Research Result}

The results of study that were discussed in this article, was a part of the research of development and implementation of thematic assignment, performed in Sangihe, year of 2014. The results of the research presented here focuses on the democratization of learning which includes three main phases namely the development of the design, implementation and evaluation.

\subsection{Democratization in the Development Stage}

The role of teachers in the development of instruction was not maximized. Teachers only provide input of material in seven activities from 10 activities of basic thematic assignment. Teachers productively provide input to the development of activities and evaluation. Teachers provide input on the role of parent involvement, but not maximum. The constraints were due to a lack of experience in identifying the local elements and integrate it into the instructional design. Through discussions with the team of researchers, teachers can propose the case that relevant to materials and learning activities.

Teachers propose input for parent's involvement in the learning activities i.e activities of measurement, data acquisition of social-cultural and community responses to government policies related to the control of the landslide. It shows the potential of increasing the teacher capacity in designing learning materials utilizing the environments, after attending several times of a joint research activities and mentoring by faculty. Student feedback is low because students are accustomed to receiving learning materials from the teacher. Students only provide input about the location of the landslide. Students have not been able to identify the relevant material and learning activities. Involving students in the development of the instructional design bring their enthusiasm to participate in the implementation of thematic assignment. In the development of design phase, the students ask the purpose and usefulness of learning. Developing of thematic assignment (landslide) design in the district of Tamako, there are five parents who are directly involved. Most parents provide input through a form of thematic assignment instruction. Parents responded enthusiastically to the instructional design of the learning. Parents provide input on the matter i.e. people's behavior with regard to landslide events, government policy and public response.

\subsection{Democratization in the Implementation of the Draft}

The assessment of learning democratization during the implementation of thematic assignment was based on indicators of student activity, the role of teachers, parents and community. Description of this outcome was the result of the implementation of instructional design which the approach was from context to concept. The development of students activities, the role of teacher and parents, presented graphically in Figure 1 to Figure 4.

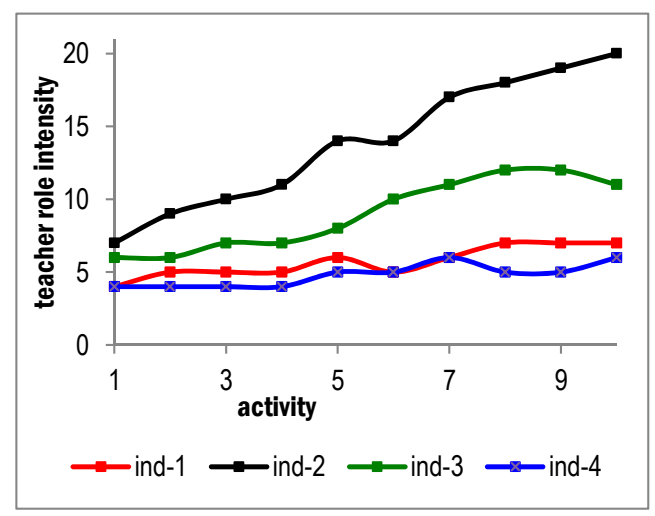

Figure 1. Teacher role progress during ten activities 


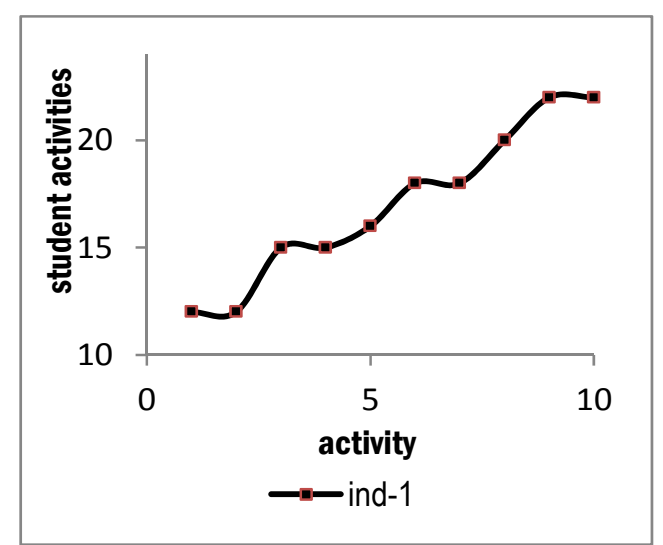

Figure 2. Student (individual) progress during ten activities

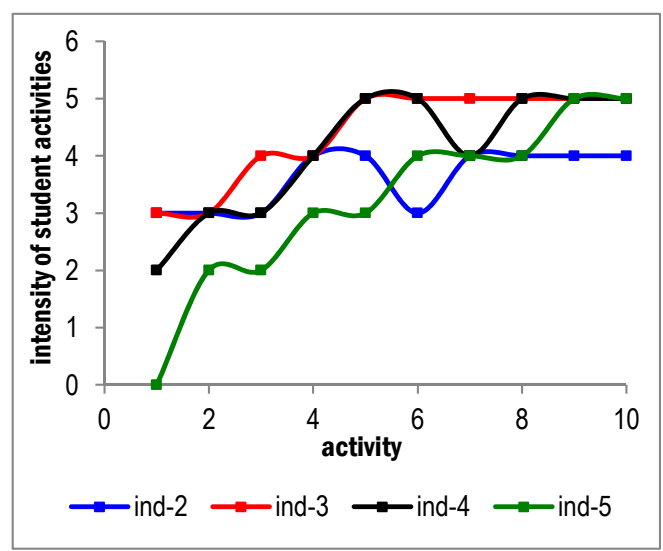

Figure 3. Student (group) progress during ten activities

Figure 1 presents a graphic of the teacher role in the implementation of the thematic assignment (landslides), ranging from first to tenth activity. In the implementation of the thematic assignment, the teacher has a high enough initiative to enable interaction in groups of students (indicator-1). The degree of teacher initiatives was related to the activity of learning group. The more active groups, teacher initiative will be increase (positive correlation coefficient). Teacher role in building a democratic learning through the dialogue with students (indicator-2), was high and increased from the first until the end of meeting. Teacher's response to the interaction within groups and across groups of students also increased from the first to the ninth meeting (indicator-3). This teacher's response was inline with the level of student groups' activity (positive correlation coefficient). During the learning process, teachers can develop materials and activities related to social issues and events around the landslide (indicator-4). Teacher shows quite good progress in building democratic learning process, especially in creating the climate of dialogical learning with students and parents.

Figures 2 and 3 show the student activity increased from the initial to the end of meeting. Individually, students proposed many relevant questions (indicator 1) primarily associated with the science procedure. Student groups can put forward alternative activity and confirm the relevance of activities with the assignment material (indicator 2). From the first to the final meeting, the students showed the increasing of communication with the research team and the teacher, about the needs of facilitation services for learning (indicator 3) and the acquisition of information (concepts) from the references (indicator 4). Implementation of thematic assignment was significantly to motivate the student initiatives (indicator 5), primarily to repeat the field measurements. 


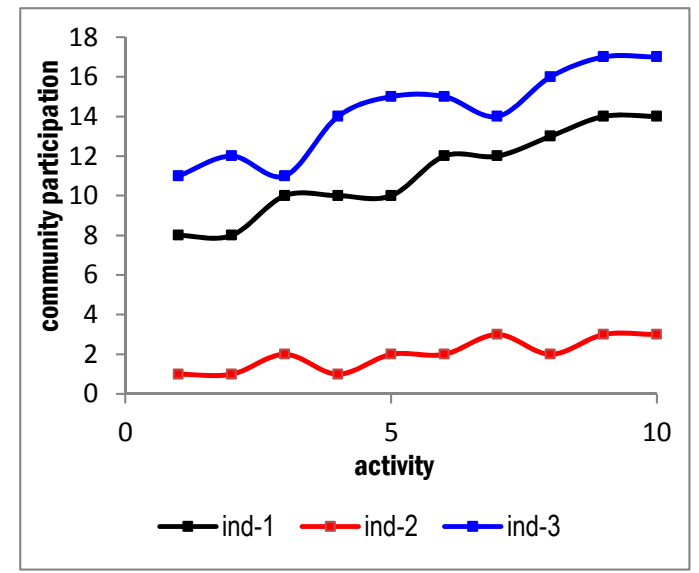

Figure 4. Parents/community role during ten activities

Participation of parents/community increased from the first to the end of meeting. Parents were active to dialogue with a team of researchers and teachers (indicator 1) regarding social issues, the community behaviors that could potentially lead to landslides, government policies on landslide control etc.

Parents actively asking the questions when they help students in the field (indicator 2), among others, on how to measure the slope, infiltration processes, root function, etc. Parents do not yet have enough experience to develop materials and activities (indicator 3), but they are satisfied because they understand the benefit of the materials of thematic assignment.

The relationship between the student's activity progress with the role of teacher and the role of parents/community, are presented in Table 1. Rank correlation coefficient was presented in Table 1 shows the relationship between the increase of student group activities with the role of teachers, and with the role of parent.

Table 1. Spearman's correlation coefficient between the increasing of student's activities and the teacher's role, and between the student activities and the parent's role

\begin{tabular}{lccccccc}
\hline \multirow{2}{*}{ Student activity indicator } & \multicolumn{3}{c}{ Indicators of teacher's role } & \multicolumn{3}{c}{ Indicators of parent's role } \\
\cline { 2 - 8 } & Ind-1 & Ind-2 & Ind-3 & Ind-4 & Ind-1 & Ind-2 & Ind-3 \\
\hline Indicator-1 & 0.876 & 0.884 & 0.812 & 0.840 & 0.812 & 0.684 & 0.902 \\
Indicator-2 & 0.722 & 0.766 & 0.746 & 0.685 & 0.693 & 0.694 & 0.784 \\
Indicator-3 & 0.815 & 0.808 & 0.820 & 0.747 & 0.712 & 0.596 & 0.778 \\
Indicator-4 & 0.606 & 0.745 & 0.770 & 0.788 & 0.820 & 0.702 & 0.812 \\
Indicator-5 & 0.587 & 0.592 & 0.594 & 0.604 & 0.546 & 0.798 & 0.663 \\
\hline
\end{tabular}

The critical value of rank correlation coefficient for $n=10$, and the significance level 0.05 was 0.564 (Crawshaw \& Chambers, 2001). Based on the classification used by the Spearman rank (Mukaka, 2012), the correlation coefficients in Table-1 was classified as moderate to very high positive. The correlation coefficient indicates a strong association between the activity of the student with the role of teacher and parents. This was also shown by the development of student activity and increasing the role of teachers and parents from the first to the final meeting. The results showed that the democratization process of learning can be built flexibility for students to interact in a group with the support of teachers, parents and the community.

\subsection{Description of the Mastery of Science-Math Concepts}

Table 2 describes the mean and variance of concepts mastery scores in physics, biology, and mathematics, after the students completed their activities on thematic assignment. 
Table 2. The mean and variance of concept mastery of physics, biology and mathematics in thematic assignment of landslide

\begin{tabular}{lcccccc}
\hline \multirow{2}{*}{$\begin{array}{l}\text { Students } \\
\text { group }\end{array}$} & $\begin{array}{c}\text { Mean of score and variance } \\
\text { in physics }\end{array}$ & \multicolumn{2}{c}{$\begin{array}{c}\text { Mean of score and variance } \\
\text { in biology }\end{array}$} & \multicolumn{2}{c}{$\begin{array}{c}\text { Mean of score and variance in } \\
\text { mathematic }\end{array}$} \\
\cline { 2 - 7 } & score & variance & score & variance & score & variance \\
\hline 1 & 7.242 & 0.033 & 7.564 & 0.038 & 7.177 & 0.026 \\
2 & 7.454 & 0.034 & 7.582 & 0.029 & 7.366 & 0.030 \\
3 & 7.125 & 0.038 & 7.325 & 0.304 & 7.034 & 0.038 \\
4 & 6.943 & 0.043 & 7.345 & 0.406 & 6.681 & 0.043 \\
5 & 7.040 & 0.034 & 7.640 & 0.342 & 7.022 & 0.041 \\
6 & 7.551 & 0.036 & 7.661 & 0.392 & 7.562 & 0.034 \\
\hline
\end{tabular}

The mean and variance data of concepts mastery in physics, biology and mathematics, which are presented in Table 2, showed that the average score is almost equal to six groups of students. The mean of variance was low for all groups of students, this indicate that the student groups was homogen. Mean scores indicate that the mastery of concepts of physics, biology and maths can be considered fairly good to good, The correlation coefficient between the average score of physics concepts with the biology of 32 students was 0.77 . The correlation coefficient between the average scores of physics concept with the mathematic concepts of 32 students was 0.86 . The correlation coefficient between the average scores of the mathematical and biology concept for 32 students was 0.71 . These correlation coefficients were significant at the significance level 0.05 . The correlation coefficient indicates that the material and activity potentially to build the comprehencive knowledge and the relationship between the concepts of science (physics and biology) with mathematics.

\subsection{Democratization in Learning Assessment and Evaluation}

During the assessment process of learning, all groups of students to clarify the results of the assessment. There were 27 students among 32 students to clarify the results during the learning process and after receiving the results of the evaluation. Students who did and who did not clarify the assessment and evaluation expressed satisfaction after getting the teacher's explanation. Students individually or in groups, motivated to improve learning activities after getting the results of the dialogical assessment and evaluation. This was shown by the increasing of activities of student groups as in Figure-2. Students response to the process of assessment and evaluation, was commented by their teacher as a significant development of open and dialogical learning, because this has never happened before.

\section{Discussion}

The development of thematic assignment of landslide and its implementation can build a learning climate that is more open and productive between students, teachers and parents/community. The involvement of students, teachers, parents and the community in the development stage can build communicative climate to carry out learning activities. Discussions during the instructional development stage can motivate students and parents. Students and parents perceived the instructional design as suitable and usefulness to cover the real problems. Although the information provided by parents was limited, but it was encourage them to engage in learning activities of students. Parents who are involved in the instruction development, motivating the other parents and they had a communication in fill-out a thematic assignment instruction. Despite performed for the first time, but the introduction of parents, students and teachers on the theme of the thematic assignment, allows them to develop the instructional design with the relevant local elements. The achievement of student learning is quite good, indicating that the initiation of collaboration in the development of the design can encourage students to learn more actively and ultimately contribute the students' knowledge construction. This result is consistent with the results of the study by Flowers et al. (1999), that the joint planning, the creation of a positive work climate, and contact between teams with parents can improve student achievement scores. Development and implementation of thematic assignment, was simultaneously reduce student dependence on teachers, and build parental support. This was required in the development of the democratization of learning.

Student activity, the role of the teacher, and parent participation in the implementation of the thematic assignment showed consistent improvement from the initial to the end of meeting. This increase occurs because the active interaction between the three components. This interaction shows that the instructional design and 
implementation of thematic assignment can encourage dialogic communication as a measure of the increase in the democratization process of learning. Though at the beginning of the process, there was the stiffness, but growing of motivation can enhance active communication and a climate of openness during the learning process. Conformity of the development of students activities with the role of the teacher and parents, to indicate that the democratization of learning process can thrive when there was intensive interaction between the components. Significant correlation between indicators, was shown that the intensive interaction between learning components, will encourage the increasing of democratic learning activities. This democratic learning activities, contribute the increasing of knowledge, science process skills (measuring, analyzing, etc.) as well as the students' views and attitudes towards conservation of resources. Stephens (2007) suggested that this learning activity ensure the development of multiple-intelligence. Integrating concept and context of landslide, was improving the multiple intelligence. According to Zandvliet and Sammel (2001), the teaching which connects the concept of science, technology, society and the environment, can integrate the increasing of knowledge, skill and affection. Higins (2002) suggests that learning about the facts around the student could potentially increasing the students' knowledge and understanding of the natural systems and processes related to environmental responsibility.

Activities conducted outside the classroom, increasing student activity in the group as well as the interaction of students with teachers and parents. The results of the assessment by researcher team, showed that the activities carried on outside the classroom makes the students had the courage to ask, answer questions, put forward ideas etc. Thematic learning that to confront the fact around students, and conducted outside the classroom, can build a democracy that ultimately contribute to student learning of knowledge, skills and affection of the problems experienced in everyday life. Democratic learning process experienced by students, to encourage the students to study the social implications of science processes, such research by Eggert et al., (2013). Thematic assignment that confronts students with authentic problems, to build student's initiatives in developing the science process as observing and discussing science. The low variance of score indicates that the implementation of the democratic thematic assignment involving the role of parents and teachers as facilitators, can improve the homogeneity of the learning achievement of groups. This result was in line with the research by Bolak et al, (2005). The open assessment and evaluation of learning processes to encourage students to perform learning initiatives, improving group learning activities and healthy competition between groups. Students gain an understanding that actually the learning process was student activity facilitated by the teacher. Students not only receive information (learning) set by the teacher, but must be actively getting resources and the process of science.

Implementation of thematic assignment raises democratic learning activities such as: (1) the initiative interaction between middle and high school students, (2) the process of assessment and reflection assignments by groups of students, (3) the activities of science process that simultaneously with the socio-cultural discussion, (4) initiative of students gain learning resources, (5) teachers and students to discuss the forms of community activities to be developed as a thematic assignment. This activity was an important input for the development of democratic learning over the next five years. Based on the results of the first year of research, the development of democratic learning through thematic assignment include: (1) the expansion and adaptation of thematic assignment according to the characteristics of the school environment, (2) the development of thematic assignment across levels of education, (3) the integration of assessment and reflection process in the implementation of the thematic assignment, (4) development of thematic assignment with socio-scientific approach, (4) the integration of the local with the global element, (5) utilizing community activities as a form of material and thematic assignment activities.

\section{Conclusion}

Development of design stage could potentially be the beginning of the democratization process of learning through thematic task. Teachers, students, and parents have not been optimal role in the development of design and need more experience through research and advocacy by the research team. Implementation of thematic task can build and enhance the democratic learning process. Students showed increased of democratic learning activities, from the initial to the end of the meeting. Democratic activity of students, increased interactively with the increasing of the role of teachers and parents. Student group activities can encourage the development of democratic learning process and contribute to mastery of concepts and processes of science. The dialogical assessment and evaluation can build a democratic attitude of students, among others, to clarify, understand and accept the results of the assessment. Overall, the results showed that the democratization of learning can be developed through thematic assignment involving the role of parents.

\section{Acknowledgements}

The research team would like to thank to the undergraduates, master's and doctoral students as well as alumni 
who were involved in this research. Thanks also to the Bupati Sangihe, to the Head of Education Office of Sangihe and her staff, the school and the teachers, and the community that were facilitating and accommodating the research team during the implementation of research in Sangihe.

\section{References}

Aref, F., Redzuan, M., \& Gill, S. S. (2009). Dimensions of Community Capacity Building: A Review of its Implications in Tourism Development. Journal of American Science, 5(8), 74-82.

Barton, K. C., \& Smith, L. A. (2000). Themes or motifs? Aiming for coherence through interdisciplinary outlines. The Reading Teacher, 54(1), 54-63.

Beane, J. A. (1997). Curriculum integration: Designing the core of democratic education. Alexandria, VA: Association for Supervision and Curriculum Development.

Bekoe, R., \& Quartey, E. F. (2013). Assessing Community Participation in Promoting Basic Education at the Akorley District Assembly (D/A) Basic School in the Yilo Krobo Municipality-Eastern Region-Ghana. Journal of Education and Practice, 4(7), 124-134.

Bolak, K., Bialach, D., \& Dunphy, M. (2005). Standards-based, thematic units integrate the arts and energize students and teachers. Middle School Journal, 31(2), 57-60.

Bransford, J., Brown, A., \& Cocking, R. (1999). How people learn: Brain, mind, experience, and school. Washington, DC: National Academy Press.

Broda, H. W. (2007). Schoolyard-Enhanced Learning. Portland. Maine: Stenhouse Publishers.

Crawshaw, J., \& Chambers, J. (2001). A Concise Course in Advanced Level Statistics with worked examples. Cheltenham: Nelson Thornes.

DiSessa, A. (2000). Changing Minds: Computers, Learning, and Literacy. Cambridge, MA: MIT Press.

Eggert, S., Ostermeyer, F., Hasselhorn, M., \& Bögeholz, S. (2013). Socioscientific decision making in the science classroom: The effect of embedded metacognitive instructions on students' learning outcomes. Education Research International. http://dx.doi.org/10.1155/2013/309894

Fettes, M. (2013). Imagination and Experience: An Integrative Framework. Democracy and Education, 21(1), Article 4. Retrieved from http://democracyeducationjournal.org/home/vol21/iss $1 / 4$

Flowers, N., Mertens, S. B., \& Mulhall, P. F. (1999). The impact of teaming: Five research-based outcomes. Middle School Journal, 36(5), 9-19.

Fogarty, R. (1997). Problem-Based Learning and Other Curriculum Models for the Multiple Intelligences Classroom.

Heller, P., Keith, R., \& Anderson, S. (1992). Teaching problem solving through cooperative grouping. Part 1: Group verses individual problem solving and Part 2: Designing problems and structuring groups. American Journal of Physics, 60(7).

Higgins, P. (2002). Outdoor education in Scotland. Journal of Adventure Education and Outdoor Learning, 2(2), 149-168.

Keith, T. Z., \& Cool, V. A. (1992). Teaching models of school learning: Effects of quality of instruction, motivation, academic coursework, and homework on academic achievement. School Psychology Quarterly, 7, 209-226.

Krogh, S. (1990). The Integrated Early Childhood Curriculum. New York: McGraw-Hill.

Letterman, M. R., \& Dugan, K. B. (2004). Team Teaching a Cross-Disciplinary Honors Course: Preparation and Development. College Teaching, 55(2), 76-79.

Linn, M. C., \& His, S. (2000). Computers, teachers, peers: Science learning partners. Mahwah, NJ: Lawrence Erlbaum Associates.

Mandang, T. (2013). The survey report in order to develop instructional thematic assignments models of integration the local context with the global context based on concept network. Department of Physics, Manado State University.

Marpaung, A. (2014). Analysis of teacher's readiness and needs to develop the traditional games for learning thematic material (Science and Mathematics) (Thesis, Department of Physics, Manado State University).

McDermott, L. C. (1993). Guest comment: How we teach and how students learn-A mismatch? American 
Journal of Physics, 61, 295-298. http://dx.doi.org/10.1119/1.17258

Medellu, Ch. (2013). The survey on the teacher readiness to design and implement the learning derived from the surrounding environment. Physics Department, Manado State University.

Medellu, Ch. (2014). Designing of thematic assignment with the socioscientific approach. LP2AI Manado State University.

Mukaka, M. M. (2012). A guide to appropriate use of correlation coefficient in medical research. Malawi Med Journal, 24(3), 69-71.

Noel, J. (2006). Science changes set to inspire students. Physics Education, 41(2), 174-178. http://dx.doi.org/10.1088/0031-9120/41/2/009

Northwest Regional Educational Laboratory, Portland, Oregon. (2005). Research based strategies: In Focus on Effectiveness. Retrieved from http://www.netc.org/focus/strategies/coop.php

Ozcan, M. (2005). The Education We Need: Democratic, Diversified and Experiential, RIC, Issues In Teaching and Learning, Volume 4. Rhode Island College. Retrieved from http://www.ric.edu/itl/volume04_ozcan

Pendrill, A. M. (2005). Rollercoaster loop shapes. Physics Education, 40(6), 517-521. http://dx.doi.org/10.1088/0031-9120/40/6/001

Popov, O. (2008). Developing Outdoor Physics Project Using Activity Theory Framework. Retrieved from http://www.diva-portal.org/smash/get/diva2:318676/FULLTEXT01.pdf

Rasubala, S. (2014). Teacher readiness and the needs to develop science and mathematics learning in integrated manner using information technology (Thesis, Department of Physics, Manado State University).

Raturandang, J. (2013). The survey reports in order to develop the thematic assignments instructions, with self and cross refection. Department of Biology, Manado State University.

Rende, J. (2013). The survey report in order to develope thematic assignments design across levels of education. Physics Department, Manado State University.

Smith, M. K. (1999). Education for Democracy. Retrieved from http://www.infed.org/biblio/b-dem.htm

Stephens, P. J. (2007). Does Integrated Thematic Instruction Motivate and Engage Culturally and Linguistically Diverse Students in Self-Directed Learning? Teacher's Network Leadership Institute Fellow North Dade Center for Modern Languages. Retrieved from http://teachersnetwork.org/tnli/research/stephens.pdf

Stetsenko, A. (2005). Activity as Object-Related: Resolving the Dichotomy of Individual and Collective Planes of Activity. Mind, Culture, and Activity, 12(1), 70-88. http://dx.doi.org/10.1207/s15327884mca1201_6

Tumangkeng, J. (2013). The survey report in order to develop models of community participation in the development of thematic learning in Sangihe regency. Department of Physics, Manado State University

Walberg, H. J. (1999). Productive teaching. In H. C. Waxman, \& H. J. Walberg (Eds.), New directions for teaching practice and research (pp. 75-104). Berkeley, CA: McCutchen Publishing Corporation

Wentworth, J., \& Davis, J. R. (2002). Enhancing Interdisciplinarity through Team Teaching. In C. Hayes (Ed.), Innovations in Interdisciplinary Teaching. Westport, CT: The Oryx Press.

Wood, K. (1997). Interdisciplinary instruction: A practical guide for elementary and middle school teachers. Upper Saddle River, N.J.

Zandvliet, D., \& Sammel, A. (2001). Exploring the connections between science and environmental education. Paper presented at the Environmental Education and Communications Conference, Whitehorse, Yukon, Canada.

\section{Copyrights}

Copyright for this article is retained by the author(s), with first publication rights granted to the journal.

This is an open-access article distributed under the terms and conditions of the Creative Commons Attribution license (http://creativecommons.org/licenses/by/3.0/). 